\title{
The development and fine structure of Lankesterella cf. dicroglossi (Apicomplexa: Lankesterellidae) infecting frogs in Niger, West Africa
}

\author{
Ilan Paperna ${ }^{1}$ and Coralie Martin $^{2}$ \\ ${ }^{1}$ Department of Animal Sciences, Faculty of Agriculture of the Hebrew University of Jerusalem, Rehovot 76-100, Israel; \\ ${ }^{2}$ Laboratoire de Biologie Parasitaire, Museum National d'Histoire Naturelle, 61 Rue Buffon, 75231 Paris cedex 05, France
}

Key words: Lankesterella cf. dicroglossi, infection, ultrastructure, frog, Hoplobatrachus occipitalis, Niger, Africa

\begin{abstract}
One of four Hoplobatrachus occipitalis (Günther, 1859) frogs received from Niger, West Africa was heavily infected with Lankesterella blood and pre-erythrocytic stages. Infected blood and tissues from this frog were force-fed to the remaining three frogs. Two survived to necropsy on days 14 and 27 post-feeding and were found to be infected with gamogonic and oogonic stages, respectively. The source of infection is inconclusive, as a natural origin cannot be excluded. Microgamont, macrogamont, oocyst and sporozoite structure and fine structure are described and found to conform in general, but not in detail, to previous descriptions. Gamonts and oocysts occurred predominantly in the liver and spleen. Walled sporulating oocysts were situated within macrophage centres. Oocysts yielded a progeny of 32 sporozoites. Pre-erythrocytic sporozoites developed within expanded inclusions, within their host cell, from which they massively invaded the liver and spleen, and to a lesser extent the lungs and kidneys. Sporozoites occurred in a parasitophorous vacuole in the erythrocytes. Conspecificity with Lankesterella dicroglossi Paperna et Ogara, 1996 reported from the same host species in Kenya remains uncertain due to several structural and developmental differences.
\end{abstract}

The fine structure of three species of Lankesterella has been studied thus far, each from a different continent or subcontinent, namely, North (Desser et al. 1990) and South America (Lainson and Paperna 1995) and Africa (Paperna and Ogara 1996). All three species show similar fine structural features in their course of differ-entiation from macrogamonts to oocysts. These features are unique and have not been observed during the development of species of Schellackia (Ostrovska and Paperna 1987, Paperna 1992, Paperna and Finkelman 1992), other members of the family Lankesterellidae (Desser 1993), or any other coccidian infecting verte-brate hosts. Tse et al. (1986) further demonstrated that leeches transmit Lankesterella by bite rather than by being ingested, as occurs in the case of Schellackia transmission via arthropod vectors (Klein et al. 1988, Bristovetzki and Paperna 1990). In this communication we present a light and electron microscopic description of a Lankesterella species from the frog Hoplobatrachus occipitalis (Günther, 1859) from Niger, West Africa, which further confirms the distinctive structural charac-teristics of Lankesterella.

\section{MATERIALS AND METHODS}

Four adult frogs of the species Hoplobatrachus occipitalis were collected around Niamey, Niger, in August 1998. The frogs were identified by Dr. Marinus S. Hoogmoed, curator of reptiles and amphibians at the National Natural History Museum in Leiden. Blood for parasitological examination was obtained by clipping the frogs' fingers. One frog with sporozoites in its blood was killed with chloroform and necropsied. In an attempt to induce gamogonous development, heart blood and pieces of the liver, spleen and lungs were force-fed to the remaining three frogs. Two were killed 14 and 27 days post-feeding (p.f.) and the last died on day 42 p.f. Blood films were made from the necropsied frogs and smears and touch preparations were made from the liver, lungs, spleen and kidneys. Pieces of these tissues were fixed for light microscopy (LM) and transmission electron microscopy (TEM). Films, smears and touch preparations were air-dried, fixed with absolute methanol and stained with Giemsa in phosphate buffer, $\mathrm{pH} 7.4$, for $1 \mathrm{~h}$.

For LM histology, tissues were fixed in $10 \%$ neutralbuffered formalin, and after dehydration in a graded ethanol series were embedded in glycol-methacrylate medium (GMA of Agar Comp., UK). Sections, 3-4 $\mu \mathrm{m}$ thick, which were cut with a glass knife on a Sorval JB4 microtome, were stained with either Meyer's haemalum-eosin, or, after a $20 \mathrm{~min}$ incubation in Bouin's solution and a rinse with water and 70\% ethanol, with $10 \%$ Giemsa, in phosphate buffer $\mathrm{pH}$ 7.4.

For TEM, tissue segments were fixed in $2.5 \%$ glutaraldehyde in cacodylate buffer $(0.1 \mathrm{M}, \mathrm{pH} 7.4)$ for $24 \mathrm{~h}$ at $4^{\circ} \mathrm{C}$, rinsed repeatedly in the same buffer, post-fixed in $1.0 \%$ osmium tetroxide in the same buffer for $1 \mathrm{~h}$ and, after rinsing in the buffer, dehydrated in a graded ethanol series and embedded in Agar 100 medium (Agar Scientific, Ltd., UK). Thin sections, cut on a Reichert Ultracut microtome with a diamond knife, were stained on-grid with uranyl acetate and lead citrate, and examined with a JEOL 100CX TEM. Semithin sections were stained with toluidine blue for examination by LM. 


\section{RESULTS}

The results of successive examinations, necropsies and parasitological findings are summarised in Table 1. Initial blood examination revealed infection in only one of the four frogs (frog 3, with a parasitaemia level of 35\%). Although the tissues and blood of frog 3 were heavily infected with seemingly differentiated sporozoites, none of the remaining three frogs, force-fed infected tissues and blood from frog 3, developed heavy infection. In frog 1, sacrificed 14 days p.f., young and mature macrogamonts and microgamonts were found mainly in the liver, and a scanty sporozoite infection was found in the erythrocytes. Frog 2, sacrificed 27 days p.f., was infected by a fair number of oocysts at variable stages of sporulation, located mainly in the liver, with a few also in the spleen. Frog 4 was examined post-mortem (42 days p.f.) and found to be uninfected.

\section{Lankesterella cf. dicroglossi Paperna et Ogara, 1996}

\section{Microgamonts}

Only one immature microgamont $12 \times 10 \mu \mathrm{m}$ in size, with 18 to 20 peripherally positioned nuclei (Fig. 1) and a $14 \times 9 \mu \mathrm{m}$ mature microgamont with differentiated microgametes (Fig. 2) were seen in LM-examined cross sections of the liver. Both stages contained numerous, variable-sized, translucent inclusions.

TEM images of the early microgamont showed nuclei with a distinct karyosome (nucleolus?). Centrioles were already present along the cell boundary.
Further differ-entiated microgamonts (Fig. 3) contained about 12 peripherally positioned nuclei adjoining a centriole. Scattered nuclear chromatin contained fragmented karyosomes. Amylopectin granules were small, bean-shaped and partly aggregated beneath the cell wall.

\section{Macrogamonts}

Macrogamonts were seen mostly in LM-examined sections of the liver, rarely in the spleen and lungs (Table 1). They were $10-18 \times 10-11 \mu \mathrm{m}$ in size $(\mathrm{n}=6)$, recognisable by their vesiculate nucleus which contained a large conspicuous nucleolus, and were lodged in a spacious parasitophorous vacuole (PV), either inside what seemed to be a hepatocyte, or a melanin-bearing macrophage. Their cytoplasm contained several large lipid vacuoles, amylopectin granules, and eosinophilic ("wall forming-like") bodies (Fig. 4).

In TEM images (Figs. 5-7), amylopectin granules were seen along the macrogamont boundary. The plasmalemmal surface was coated by a fine granular glycocalyx. Large lipid inclusions were seen. The nucleolus consisted of loosely or densely aggregated electron-dense globules (Figs. 5, 7). The cytoplasm contained numerous whorls of rough endoplasmic reticulum, vesicles (or vacuoles) and inclusions filled with sparse granular content, one or two structures reminiscent of adnuclear bodies and a few large electrondense ("wall-forming-like") bodies (Fig. 7), which corresponded with the eosinophilic spheres in LM.

Table 1. Flow chart of events and findings in the study of the Lankesterella cf. dicroglossi infection in frogs (d.p.f. - days post feeding).

\begin{tabular}{|c|c|c|c|c|}
\hline & Frog 1 & Frog 2 & Frog 3 & Frog 4 \\
\hline $\begin{array}{l}\text { Aug. } 28 \text { - frogs received, } \\
\text { blood examined }\end{array}$ & negative & negative & sporozoites ++++ & negative \\
\hline Sep. 9 - blood examined & negative & negative & sporozoites ++++ & negative \\
\hline Sep. 9 - necropsy & & & $\begin{array}{l}\text { sporozoites in blood, liver } \\
\text { and spleen }(++++) \text {, and in } \\
\text { lungs and kidneys }(++)\end{array}$ & \\
\hline $\begin{array}{l}\text { Sep. } 9 \text { - experimental } \\
\text { infection }\end{array}$ & $\begin{array}{l}\text { fed on blood and tissues } \\
\text { of frog } 3\end{array}$ & $\begin{array}{l}\text { fed on blood and } \\
\text { tissues of frog } 3\end{array}$ & & $\begin{array}{l}\text { fed on blood and } \\
\text { tissues of frog } 3\end{array}$ \\
\hline $\begin{array}{l}\text { Sep. } 23 \text { (14 d.p.f.) - } \\
\text { necropsy }\end{array}$ & $\begin{array}{l}\text { free sporozoites in } \\
\text { blood }(+) \text {; macro- } \\
\text { gamonts and micro- } \\
\text { gamonts in liver }(++) \text {, } \\
\text { lungs and spleen }(+)\end{array}$ & & & \\
\hline $\begin{array}{l}\text { Oct. } 6 \text { ( } 27 \text { d.p.f.) - } \\
\text { necropsy }\end{array}$ & & $\begin{array}{l}\text { sporoblasts } \\
(++++) ; \text { free } \\
\text { sporozoites }(++) \\
\text { in liver and spleen }\end{array}$ & & \\
\hline $\begin{array}{l}\text { Nov. } 26 \text { ( } 42 \text { d.p.f.) - post- } \\
\text { mortem examination }\end{array}$ & & & & died, negative \\
\hline
\end{tabular}



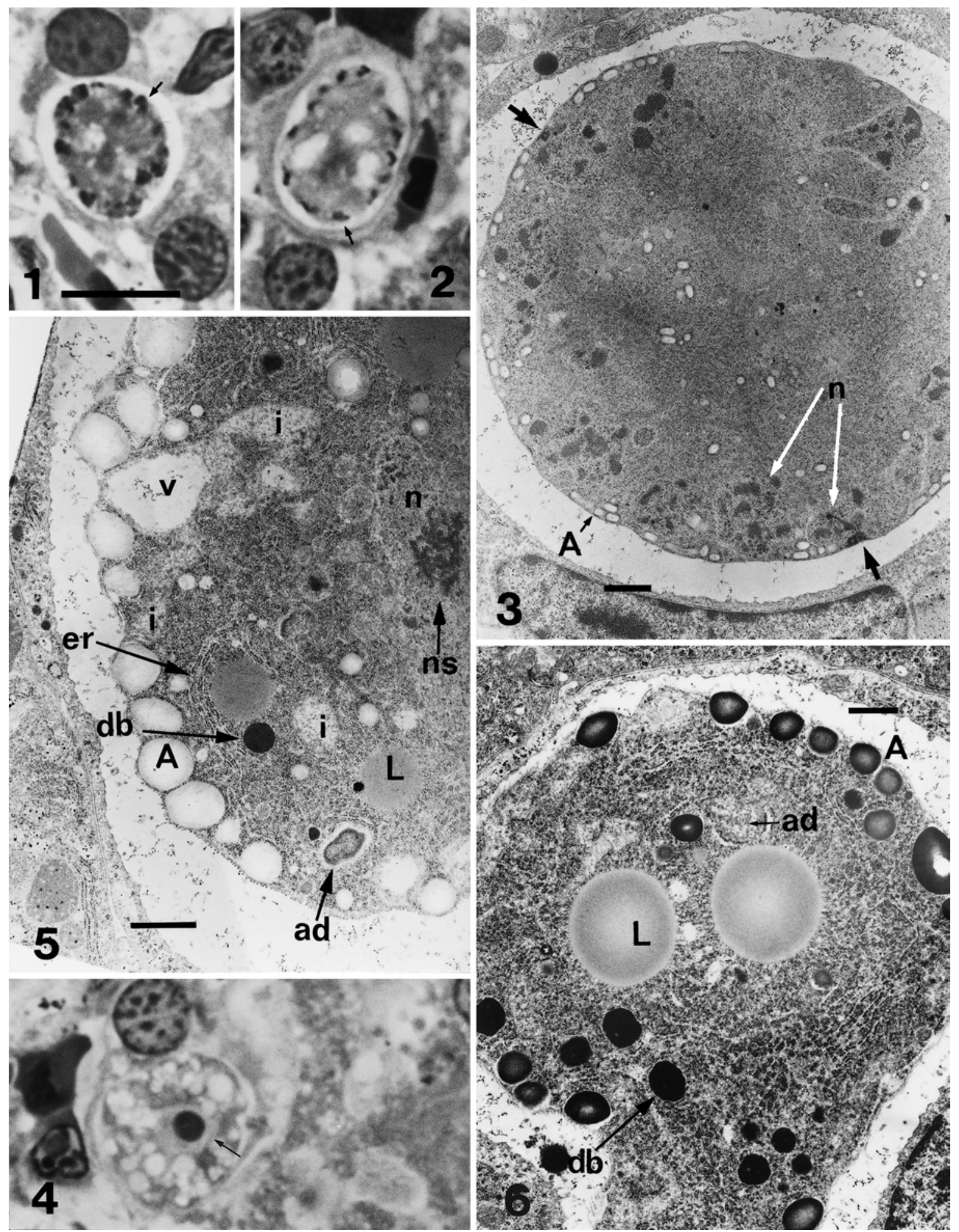

Figs. 1-6. Gamogonic stages of Lankesterella cf. dicroglossi in the liver of Hoplobatrachus occipitalis. Fig. 1. Immature microgamont fringed with nuclei (arrow); LM, GMA, Bouin-Giemsa. Fig. 2. Mature microgamont fringed with microgametes (arrow); LM, GMA, Bouin-Giemsa. Fig. 3. Immature microgamont with peripherally arranged nuclei (n), adjacent centrioles (arrow) and amylopectin granules (A); TEM. Fig. 4. Macrogamont (arrow, nucleus with the large nucleolus); LM, GMA, BouinGiemsa. Figs. 5, 6. Macrogamonts; TEM. A - amylopectin granules; ad - adnuclear body; db - electron-dense bodies; er endoplasmic reticulum; $\mathrm{i}$ - inclusions; $\mathrm{L}$ - lipid vacuole; $\mathrm{n}$ - nucleus; $\mathrm{ns}$ - nucleolus; v - vesicles. Scale bars: Fig. 1 (same scale for Figs. 2, 4) $=10 \mu \mathrm{m}$; Figs. 3, 5, $6=1 \mu \mathrm{m}$. 

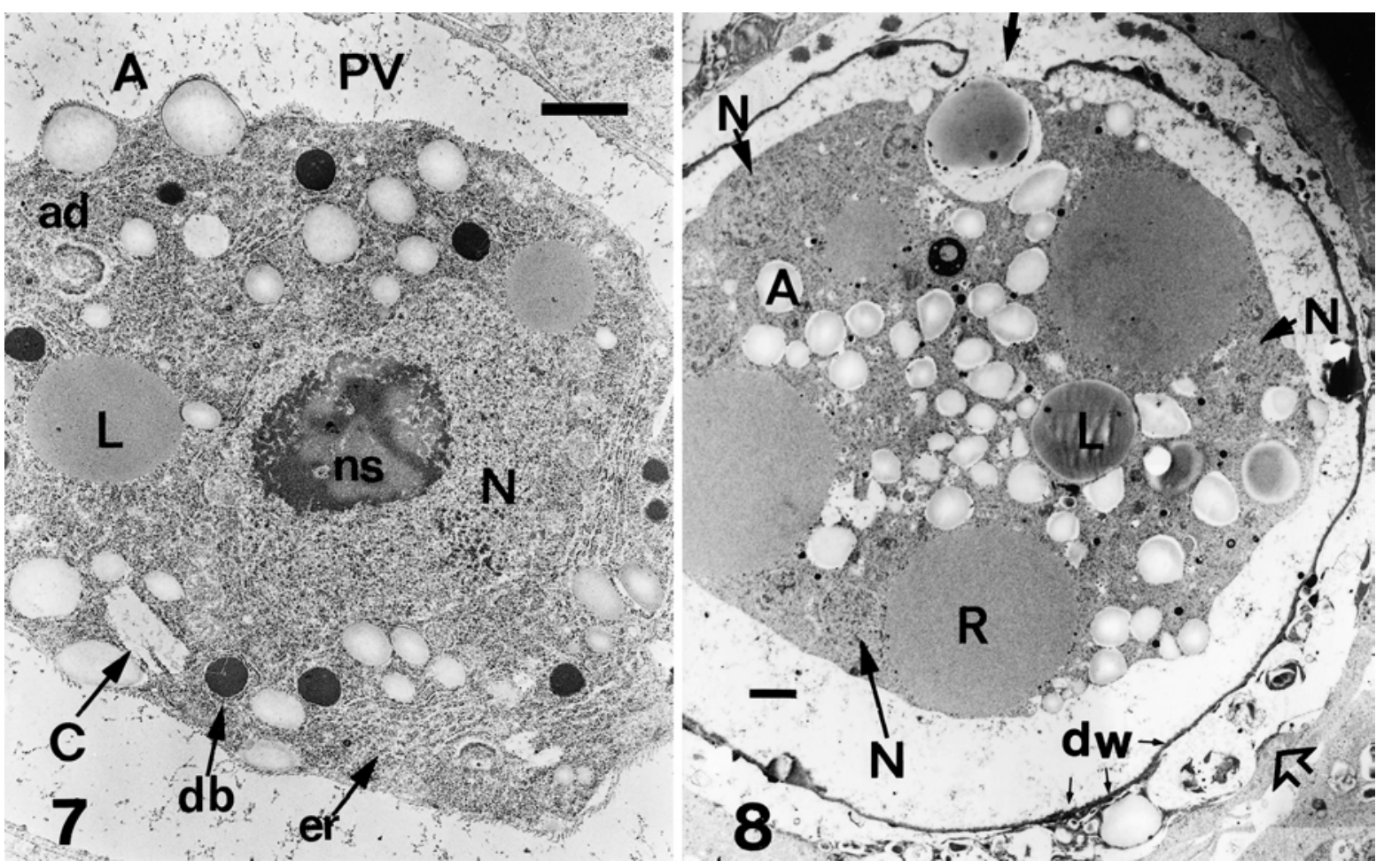

Fig. 7. Macrogamont of Lankesterella cf. dicroglossi showing details of its nucleus. Fig. 8. A sporoblast of $L$. cf. dicroglossi with divided refractile bodies anlagen and enclosed in an electron-dense deposited envelope (dw) with a gap at one apex (arrow). The host cell appears degenerate (see open arrow). A - amylopectin granules; ad - adnuclear body; $\mathrm{C}$ - canaliculi; db - dense (wall-forming-like) bodies; er - endoplasmic reticulum; L - lipid inclusion; $\mathrm{N}$ - nucleus; $\mathrm{ns}$ - nucleolus; PV - parasitophorous vacuole; $\mathrm{R}-$ refractile body. Scale bars: Figs. 7, $8=1 \mu \mathrm{m}$.

\section{Sporulating oocysts}

Zygotes accumulated amylopectin bodies and assumed an oval-compact shape. Sporoblasts, with divided nuclei, were invested by a thin, dense wall. These stages contained large lipid vacuoles, some amylopectin granules and anlagen of the refractile bodies. The entire sporulation process up to the release of sporozoites occurred within melanomacrophage centres (Table 1, Figs. 8-14). The sporoblast was located within an expanded PV of a putative macrophage, with its nucleus displaced to its margins (Figs. 9, 12), or embedded in residues of defunct cells (Figs. 8, 13). TEM images showed the formation of a wall or envelope of deposited electron-dense substance (Fig. 8). Additional layers were added to the PV-side surface (Fig. 9). A gap in this envelope, with folded rims, occurred in all observed sporoblasts (Fig. 8), which appeared to be in the midst of sporulation: nuclei divided along with the refractile anlagen while displacing the amylopectin granules and a several large lipid vacuoles (Fig. 8). The rims of the sporoblasts were heavily invaginated in some sectors as well as being fringed with many amylopectin granules (Fig. 9); the daughter nuclei were accompanied by a Golgi complex
(Fig. 10). Figs. 11-14 present LM images of sporoblasts differentiating from a single nucleus (oocyst) to a late stage of sporozoite formation. Sectioned sporoblasts were $21-29 \times 18-26 \mu \mathrm{m}$ in size $(\mathrm{n}=11)$ and showed up to 20 nuclei or sporozoite primordia, with an estimated progeny of 32. The envelope seen as electron-dense in TEM could also be detected in LM (Figs. 12-14); the lumen enclosed by the envelope sometimes showed dense content (Fig. 12).

\section{Infection by sporozoites}

The liver and spleen contained large aggregates of sporozoites 7.0-8.0 $\times 1.9-2.2 \mu \mathrm{m}$, in size $(\mathrm{n}=10)$; each sporozoite was located within a large vacuole or inclusion (Figs. 15, 16). Smaller aggregates were seen in the lungs (Fig. 17) and only a few sporozoites were detected in the kidneys (Table 1).

Viewed by TEM, the sporozoites in their host cells were contained within an expanded inclusion bound by a fine lamina (Figs. 18-20); some of the host cells noctained more than one sporozoite-bearing inclusion (Fig. 21). This parasitophorous inclusion contained sparse granular matrix with some remnants of organelles and sloughed membranes, seemingly products of both 


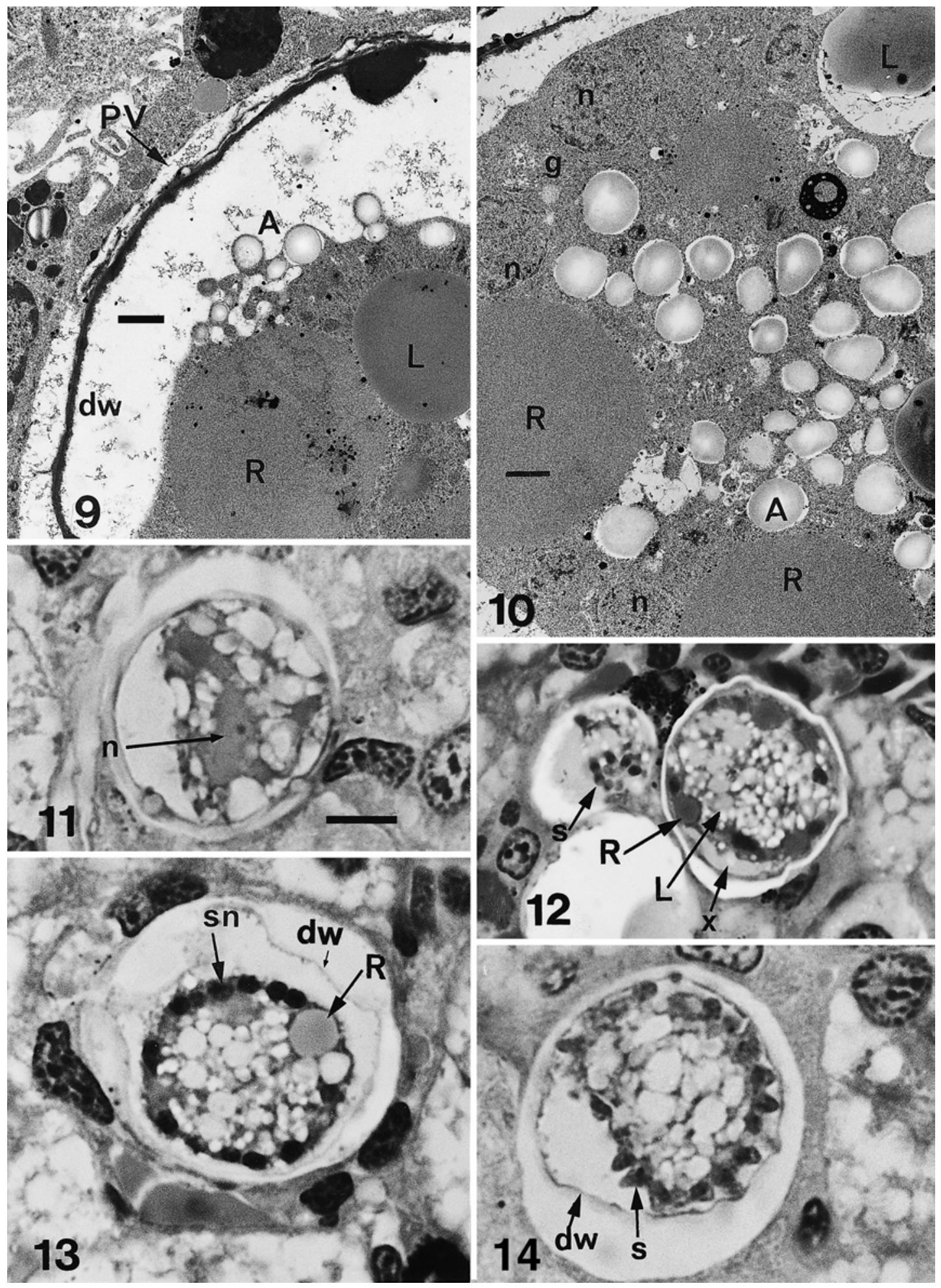

Figs. 9, 10. Sporoblasts of Lankesterella cf. dicroglossi lodged within PV, invested in an electron-dense envelope (dw), with divided nuclei (n) and adjacent Golgi complex (g), refractile body anlagen (R) and amylopectin granules (A); TEM. Figs. 11-14. Sporulating oocysts of $L$. cf. dicroglossi; LM - semithin, toluidine blue-stained. Fig. 11. Early oocyst, with a single nucleus (n). Figs. 12, 13. Sporoblasts invested in an envelope, showing daughter nuclei at the periphery and loaded with amylopectin granules. The lumen $(\mathrm{x})$ enclosed by the envelope has a denser consistency. Fig. 14. Sporoblast with emerging sporozoites. dw dense envelope; L - lipid vacuoles; $\mathrm{R}$ - refractile body-anlagen; s - sporozoites; sn - daughter nuclei. Scale bars: Figs. 9, $10=$ $1 \mu \mathrm{m}$; Fig. 11 (same scale for Figs. 12-14) $=10 \mu \mathrm{m}$. 


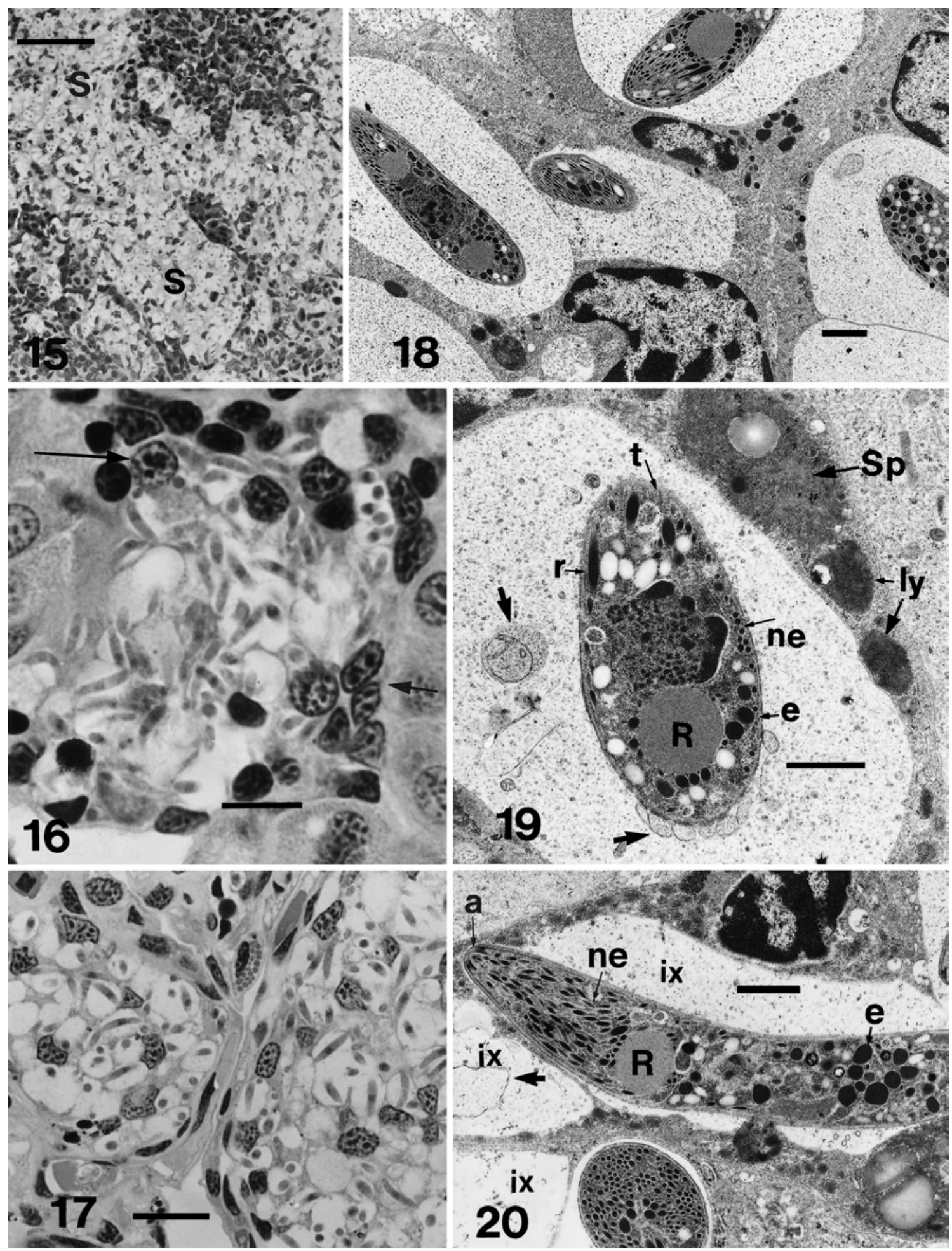

Figs. 15-20. Tissue sporozoites of Lankesterella cf. dicroglossi. Fig. 15. Massive aggregates of sporozoites (S) in the spleen. Fig. 16. Enlarged view of aggregated sporozoites in the liver (arrows, hepatocyte nuclei). Fig. 17. Enlarged view of sporozoites in the lung (Figs. 15-17; LM GMA, Bouin-Giemsa). Fig. 18. Liver tissue with sporozoites inside expanded parasitophorous inclusions; TEM. Figs. 19, 20. Enlarged view of sporozoites within macrophage. Note the sporozoite apical complex (a), rhoptries (r), microtubules ( $\mathrm{t}$ ), micronemes (ne), posteriorly positioned electron-dense bodies (e), and refractile bodies (R). The inclusion (ix) contains membranous and globular residues (arrows). Host cell cytoplasm contains naked sporozoite (Sp) and lysosomes (ly); TEM. Scale bars: Fig. $15=50 \mu \mathrm{m}$; Fig. $16=10 \mu \mathrm{m}$; Fig. $17=15 \mu \mathrm{m}$; Figs. $18-20=1 \mu \mathrm{m}$. 

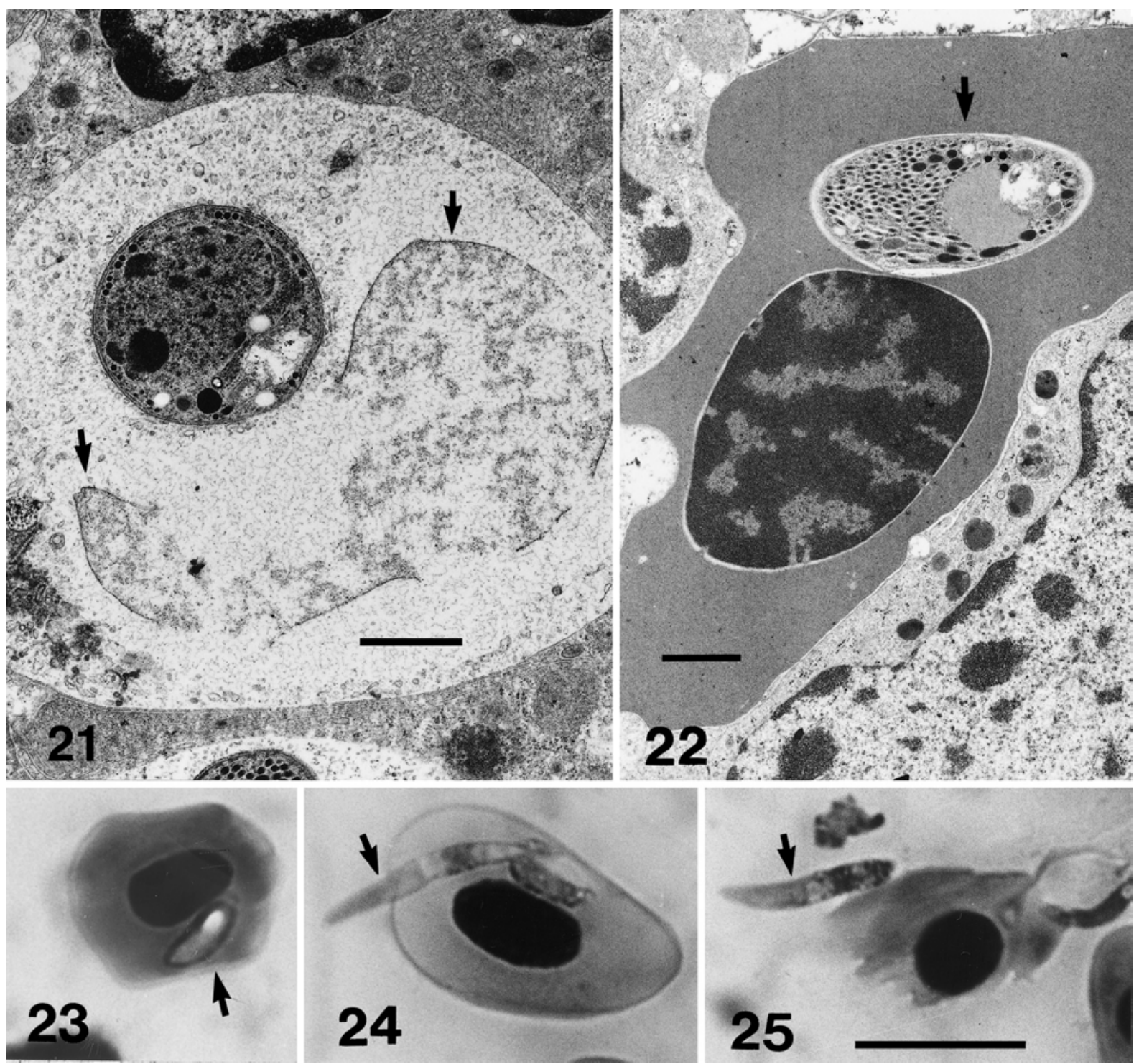

Figs. 21-25. Sporozoites of Lankesterella cf. dicroglossi. Fig. 21. Parasitophorous inclusion with a sporozoite and some residual material (arrows); TEM. Fig. 22. Sporozoite (arrow)-infected erythrocyte; TEM. Fig. 23. Infected erythrocyte (arrow: folded sporozoite). Figs. 24, 25. Sporozoite (arrow) released from its erythrocyte host-cell (Figs. 23-25 LM, Giemsa-stained blood film). Scale bars: Figs. 21, $22=1 \mu \mathrm{m}$; Fig. $25=10 \mu \mathrm{m}$ (same scale for Figs. 23, 24).

parasite (pellicle) and host-cell (PV?) origin (Figs. 19, 21). Host cells in the liver were comprised of both hepatic parenchyma and cells of the macrophage centres (Figs. $16,20,21)$. The host-cell nuclei appeared intact and their cytoplasm was loose and contained endoplasmic reticulum, intact and seemingly defunct mitochondria, lysosomes, variable organelle residues and sometimes, remains of a defunct sporozoite. Sporozoites contained rhoptries, numerous micronemes, pellicular microtubules, refractile bodies located one anterior and another posterior to the nucleus and some amylopectin granules (Figs. 18-20). Electron-dense bodies occurred in the posterior end, around the posterior refractile body (Figs. 19, 20).

Sporozoites escaping into the blood entered into erythrocytes. Sporozoites in TEM images were seen within a defined PV in the erythrocyte cytoplasm (Fig. 22). They retained the same fine structural features seen in exo-erythrocytic stages. The sporocytes lay folded in the erythrocytes (Figs. 23, 24). Blood films contained many released $12.4-14.4 \times 1.4-2.0 \mu \mathrm{m}(\mathrm{n}=10)$ sporozoites, each with two refractile bodies (Figs. 24, 25). 
H $\quad$ o s $\mathrm{s}$ t : Hoplobatrachus occipitalis (Günther, 1859) (Amphibia, Ranidae). Identified by Dr. M.S. Hoogmoed; four specimens deposited in the National Natuurhistorisch Museum Leiden, The Netherlands, under the registration number RMNH 28584-87.

L o c a 1 i t y : Niamey, Niger, West Africa.

Voucher mate ri a l: histological specimens; collection (protozoological part) of the Institute of Parasitology, Academy of Sciences of the Czech Republic, České Budějovice, Nos. PA-033 and PA-034, and Muséum National d'Histoire Naturelle, 61 Rue Buffon, 75231 Paris cedex 05, France, No. PXI 150.

\section{DISCUSSION}

Tse et al. (1986) and Desser et al. (1990) demonstrated that Lankesterella minima of the American bullfrog is transmitted via the leech vector's bite. This is in contrast to Schellackia species that are transmitted by the ingestion of the infected vector (Klein et al. 1988, Bristovetzki and Paperna 1990). Desser et al. (1990) and Paperna and Ogara (1996) suggested that Lankesterella and Schellackia cannot be grouped therefore within a same family. Although in our experiments, frogs following feeding on blood and tissue of an infected frog developed gamogonous infection, the possibility of their having been naturally infected prior to their capture cannot be excluded. Therefore, the origin of their infection remains inconclusive and can neither support nor challenge findings reported by Tse et al. (1986).

Dicroglossus occipitalis (Günther, 1859), the host of Lankesterella dicroglossi Paperna et Ogara, 1966, is the older name of Hoplobatrachus occipitalis, the host of the presently studied Lankesterella species (Dr. M.S. Hoogmoed, Natl. Natuurhist. Mus. Leiden, pers. comm.). In spite of the apparent host conspecificity and the overall conformity in sizes between corresponding developmental stages, LM data reveal some differences between the parasites from the Kenyan and the Niger frogs. Gamogonic stages, young oocysts and sporoblasts in the Kenyan frogs, which develop inside endothelial cells, tend to slough off into the capillary lumen; such sporoblasts yielded over 40 sporozoites (Paperna and Ogara 1996). In the frogs from Niger, development, in particular of the sporulating stages, even if initiated in endothelial cells, ultimately occurs inside large macrophage centres, often within a defunct host cell or its residue. Sporoblasts form about 32 sporozoites. There are no TEM data for comparison on $L$. dicroglossi from the Kenyan frogs.

In neither the $L$. dicroglossi-infected Kenyan frog, nor with any of the previously described Lankesterella, did either natural or even experimental infections develop such a high load of sporozoites as seen in the naturally infected Niger frog. These sporozoites were lodged within large vacuoles in the host cells.
In the absence of conspicuous markers for interspecific differential diagnosis of Lankesterella species and experimental evidence of the host-specificity of these parasites, naming new species is likely to be received with scepticism. Desser et al. (1990) considered Lankesterella found in North American frogs to be conspecific with L. minima (Chaussat, 1850) Noller, 1912, found in European frogs. Other species found in anurans, Lankesterella hylae Cleland et Johnston, 1910 in Australia (Stehbens 1966), L. petiti Lainson et Paperna, 1995 in Brazil (Lainson and Paperna 1995), L. bufonis Mansour et Mohammed, 1962 in Egypt (Mansour and Mohammed 1962), and L. ptychadeni and L. dicroglossi Paperna et Ogara, 1996 in Kenya (Paperna and Ogara 1996) were described as separate species. L. hylae and L. ptychadeni develop in the endothelium of the lamina propria (Stehbens 1966, Paperna and Ogara 1996) rather like the rest which are established in the reticulo-endothelium of the liver, spleen and lungs (Desser 1993). Differences in geographical distribution should be considered with caution. They could be valid on an intercontinental level; zoogeographic ties, however, between African and European frogs may be closer than usually regarded.

Fine structural data on zygotes and young oocysts are already available from four species of Lankesterella (Desser et al. 1990, Lainson and Paperna 1995, Paperna and Ogara 1996; this paper). Zygotes (and macrogamonts) of all these species of Lankesterella lack the characteristic Eimeria-type two sets of wall-forming bodies as seen in Schellackia (Ostrovska and Paperna 1987). The single-type electron-dense wall-forming-like bodies are reminiscent of those seen in zygotes of piscine and amphibian coccidia (Paperna 1995, Paperna and Lainson 1995); these organelles, likewise, do not seem to play any role in oocyst wall formation. The thin electron-dense envelope formed around the sporoblasts is unique to Lankesterella. Although this envelope has been regarded as the PV boundary (Desser et al. 1990), the presently studied images might suggest this structure to have developed from the zygote wall. The conspicuous gap in this envelope seems to be the site where a cytoplasmic bridge is established between the oocyst and the host cell, across the deposited wall, as seen in the earlier studied images of L. petiti (Lainson and Paperna 1995). This bridge occurs in L. ptychadeni where the envelope is lacking (Paperna and Ogara 1996), and is absent in L. cf. dicroglossi from the Niger frogs where an envelope with a gap appears. This might suggest that this bridging formation is part of the parasite and is retractible and the deposited envelope is a transitional structure in the sporulation process.

All Lankesterella species form refractile bodies, all characteristically fringed with electron-dense droplets. The fragmentation of the refractile material from an 
anlage in the sporoblast into refractile bodies which are incorporated into the sporozoite follows the same scenario seen in haemogregarinids with crystallinematerial anlagen (Lowichik et al. 1993, Smallridge and Paperna 1997). The involvement of refractile rather than crystalline substance in the sporogonous process in both Lankesterella and Schellackia may hint of links with eimeriid coccidia. Sporozoites of both Schellackia and Lankesterella are not only capable of withstanding the host cell's phagocytic lysosomal defence system (Mauel 1996), but after initially becoming established inside a PV, they gradually lyse the entire host cell cytoplasm (Paperna and Ostrovska 1989, present study).
Free sporozoites are common features of Lankesterella-infected blood films (Desser et al. 1990, present study and unpublished observations). This suggests that Lankesterella infection also alters erythrocyte integrity with the consequent collapse of many infected erythrocytes in the process of smear preparation. The finding of many freed sporozoites, alternatively could have been an artifact, resulting from the slower drying of the anuran more liquid smeared blood. Freed sporozoites rarely occur in blood smears infected by Schellackia species (Bristovetzki and Paperna 1990).

\section{REFERENCES}

BRISTOVETZKI M., PAPERNA I. 1990: Life cycle and transmission of Schellackia cf. agamae, a parasite of the starred lizard Agama stellio. Int. J. Parasitol. 20: 883-892.

DESSER S.S. 1993: The Haemogregarinidae and Lankesterellidae. In: J. Kreier (Ed.), Parasitic Protozoa. Vol. 4. Academic Press, New York, San Francisco, London, pp. 247-272.

DESSER S.S., SIDDAL M.E., BARTA J.R. 1990: Ultrastructural observations on the developmental stages of Lankesterella minima (Apicomplexa) in experimentally infected Rana catesbiana tadpoles. J. Parasitol. 76: 97103.

JONES T.C., HIRSCH J.G. 1972: The interaction between Toxoplasma gondii and mammalian cell II. The absence of lysosomal fusion with phagocytic vacuoles containing living parasites. J. Exp. Med. 136: 1173-1195.

KLEIN T.A., YOUNG E.C., GREINGER E.C., TELFORD S.R. Jr., BUTLER J.F. 1988: Development and experimental transmission of Schellackia golvani and Schellackia occidentalis by ingestion of blood-feeding arthropodes. Int. J. Parasitol. 18: 259-267.

LAINSON R., PAPERNA I. 1995: Light and electron microscope study of a Lankesterella petiti n. sp. (Apicomplexa: Lankesterellidae) infecting Bufo marinus (Amphibia: Anura) in Para, North Brazil. Parasite 2: 307-313.

LOWICHIK A., LANNERS H.N., LOWRIE R.C., MEINERS N.E. 1993: Gametogenesis and sporogony of Hepatozoon mocassini (Apicomplexa, Adeleina: Hepatozoidae) in an experimental mosquito host, Aedes aegypti. J. Euk. Microbiol. 40: 287-297.

MANSOUR N.S., MOHAMMED A.H.H. 1962: Lankesterella bufonis sp. nov. parasitizing toads, Bufo regularis Reuss, in Egypt. J. Protozool. 9: 243-248.

MAUEL J. 1996: Intracellular survival of protozoan parasites with special references to Leishmania spp., Toxoplasma gondii and Trypanosoma cruzi. Adv. Parasitol. 38: 1-51.
OSTROVSKA K., PAPERNA I. 1987: Fine structure of gamont stages of Schellackia cf. agamae (Lankesterellidae, Eucoccidia) from the starred lizard Agama stellio. Parasitol. Res. 73: 492-499.

PAPERNA I. 1992: Ultrastructural studies on oocysts, sporulation and sporozoites of Schellackia cf. agamae from the intestine of the starred lizard Agama stellio. Int. J. Parasitol. 22: 361-368.

PAPERNA I. 1995: Ultrastructural and developmental affinities of piscine coccidia. Dis. Aquat. Org. 22: 67-76.

PAPERNA I., FINKELMAN S. 1992: Schellackia ptyodactyli sp. n. of the fan-footed gecko Ptyodactylus hasselquistii from the rift escarpment of the lower Jordan Valley. Folia Parasitol. 43: 161-172.

PAPERNA I., LAINSON R. 1995: Life history and ultrastructure of Eimeria bufomarini n. sp. (Apicomplexa: Eimeriidae) of the giant toad, Bufo marinus (Amphibia: Anura) from Amazonian Brazil. Parasite 2: 141-148.

PAPERNA I., OGARA W. 1996: Description and ultrastructure of Lankesterella species infecting frogs in Kenya. Parasite 4: 341-349.

PAPERNA I., OSTROVSKA K. 1989: Ultrastructural studies on sporozoite stages of Schellackia cf. agamae from liver and blood of the starred lizard Agama stellio. Int. J. Parasitol. 19: 13-19.

SMALLRIDGE C., PAPERNA I. 1997: The tick transmitted haemogregarinid of the Australian sleepy lizard Tilliqua rugosa belongs to the genus Hemolivia. Parasite 4: 359363.

STEHBENS W.E. 1966: Observations on Lankesterella hylae. J. Protozool. 13: 59-62.

TSE B., BARTA J., DESSER S.S. 1986: Comparative ultrastructural features of the sporozoite of Lankesterella minima (Apicomplexa) in its anuran host and leech vector. Can. J. Zool. 64: 2344-2347. 